\title{
AN EXPLORATION OF THE RELATIONS BETWEEN FUNCTIONALITY, AESTHETICS AND CREATIVITY IN DESIGN
}

\author{
Han, Ji; Forbes, Hannah; Schaefer, Dirk \\ University of Liverpool
}

\begin{abstract}
Creativity is often said to play a vital role in the product design process, while functionality and aesthetics are considered key factors of actual products. Functionality refers to the performance of a product, and aesthetics represents the visual and ergonomic appeals of the product. However, there appears to be an elusive relation between creativity, functionality and aesthetics. This study explores how functionality, aesthetics and creativity are related to one another in design. Through exploring the definitions and assessments of creativity in design, this study reveals that novelty, usefulness and surprise are the three core elements of design creativity. A case study involving experts evaluating design samples in terms of novelty, usefulness, surprise, functionality, aesthetics and overall creativity is conducted. The results imply that there are no statistically significant relations between creativity, functionality, and aesthetics. Considering the three core elements of design creativity, the results indicate that creativity is only statistically significantly related to novelty. Moreover, our results suggest that creativity and novelty are measuring the same construct.
\end{abstract}

Keywords: Creativity, Early design phases, New product development, Functionality, Aesthetics

Contact:

Han, Ji

University of Liverpool

Industrial Design

United Kingdom

ji.han@liverpool.ac.uk

Cite this article: Han, J., Forbes, H., Schaefer, D. (2019) 'An Exploration of the Relations between Functionality, Aesthetics and Creativity in Design', in Proceedings of the 22nd International Conference on Engineering Design (ICED19), Delft, The Netherlands, 5-8 August 2019. DOI:10.1017/dsi.2019.29 


\section{INTRODUCTION}

Creativity is considered a fundamental feature of human intelligence (Cross, 2011). The human capacity for creativity and innovation has evolved over hundreds of thousands of years; driven by biological factors as well as social factors (Pringle, 2013). Despite this, creativity appears to be an abstruse issue of science.

The creative person, process, product and environment are considered to be the four core elements of achieving creativity (Couger et al., 1993; Rhodes, 1961; Thompson and Lordan, 1999). The outputs of creativity, resulting from long periods of work with a series of mini-breakthroughs, emerge from the combination of some essential mental capabilities (Childs, 2018). These outputs, such as ideas, actions and objects, are conceived to be novel, good quality, and useful (Carruthers, 2011).

Creativity has been widely considered an essential part of the design process (Chiu and Shu, 2012; Thompson and Lordan, 1999; Toh and Miller, 2015). Demirkan and Afacan (2012) claimed that creativity is a natural element of design which often occurs between the problem and solution space. Taura and Nagai (2017) indicated that creativity is a prerequisite of generating ideas for breakthrough products. Hsiao and MacDonald (2013) and Sarkar and Chakrabarti (2011) suggested creativity is an integral part of design, used for problem-solving and innovative product development. It indicates that creativity plays a vital role in the early phases of design, particularly in idea generation.

Chiu and Shu (2012) claimed that creative concepts often lead to creative and successful designs. Han et al. (2018a) suggested creativity is linked to economic benefit via design. Sarkar and Chakrabarti (2011) indicated that creativity is crucial for business portfolios and designing products, as it initiates innovations, supports problem-solving, and is closely associated with market share. Although creativity is a significant indicator of design effectiveness, customers may not explicitly state creativity as a requirement while seeking creative designs (Chiu and Shu, 2012).

Functionality and aesthetics are considered the key characteristics and success factors of products (Cropley and Kaufman, 2018; Rahman et al., 2010). Functional attributes are the actions required by a design problem, or the actions provided by the problem solutions (Chakrabarti and Bligh, 2001). This is known as the performance of a product. Aesthetics involves two different concepts: the senses, especially vision, represented by the product; and the particular cognitive response or reaction, the perception of how pleasing the product is, to the object (Crilly et al., 2004; Sonderegger and Sauer, 2010). In other words, aesthetics refers to the visual and ergonomic appeals of a product to users (Cropley and Kaufman, 2018). The functionality of a product satisfies customer needs through problem solving and prevention while the aesthetics of a product produce experiential pleasures through viewing, sense of ownership, interaction or consumption (Rahman et al., 2010). Perez Mata et al. (2017) indicated that aesthetic appeal is now used to provide consumers with additional value, in a competitive market of products with similar functionality. Also, Orsborn et al. (2009) claimed aesthetics are a crucial factor in consumers' buying decision and satisfaction. However, Sylcott et al. (2013) showed that functionality is weighted more heavily than aesthetics in assessing a design. Hagtvedt and Patrick (2014) indicated that there needs to be a balance between functionality and aesthetics in product design. Creativity plays a vital role in design as well as new product development. Sarkar and Chakrabarti (2011) claimed novelty and usefulness are the core elements of design creativity, while Christensen and Ball (2016) indicated that aesthetics, functionality and originality are the key dimensions. Thus, it appears that there is an elusive relationship between functionality, aesthetics and creativity in product design.

The aim of this paper is to explore how functionality, aesthetics and creativity are related to one another in the context of product design. In this study, functionality refers to performance, and aesthetics refers to visual and ergonomic appeals, in line with the Cropley and Kaufman (2018) study. This study will further the understanding of design creativity, as well as how people perceive design creativity. It will also deliver new insights into defining and assessing design creativity.

The following two sections investigate the commonly used definitions of design creativity and the metrics of creativity assessments, demonstrating the core elements in design creativity definition and assessment. Section 4 provides an exploration of the relations between creativity, functionality and aesthetics through a case study, following by subsequent discussions. Finally, conclusions from the research conducted and its findings are drawn in Section 5. 


\section{DEFINITIONS OF CREATIVITY}

There are many definitions of creativity varying in complexity. For instance, 'the act of making new relationships from old ideas' (Koestler, 1964); 'the process by which something so judged (to be creative) is produced' (Amabile, 1983); 'the ability to produce work that is both novel (i.e. original, unexpected) and appropriate (i.e. useful, adaptive concerning task constraints)' (Sternberg and Lubart, 1998); 'the production of novel, useful products' (Mumford, 2003); 'a response to the continual innovation and resourcefulness that have become necessary for economic survival' (Craft, 2003); 'the ability to come up with ideas or artefacts that are new, surprising, and valuable' (Boden, 2004); and 'the ability to imagine or invent something new of value' (Childs et al., 2006). It is indicated that novelty and usefulness are considered to be the core of creativity. However, most of these definitions were defined by researchers from cognitive science and psychology.

Therefore, there is a need to explore how design researchers define or describe creativity. We have reviewed 14 articles on creativity published in the recent five years. The articles were selected from top design research journals, such as Design Studies, Journal of Mechanical Design, Journal of Engineering Design, and Research in Engineering Design. These definitions of creativity were either defined, summarised, or used by the authors. The details are shown in Table 1.

Table 1. Definitions of creativity in design research

\begin{tabular}{|c|c|c|}
\hline Definitions of Creativity & Authors & Source \\
\hline $\begin{array}{l}\text { 'Creative design involves the active modification or rejection of } \\
\text { previously accepted ideas, ideas that might otherwise block } \\
\text { progress.' }\end{array}$ & Crilly (2015) & Design Studies \\
\hline $\begin{array}{l}\text { 'Creativity requires the production of novel and appropriate ideas } \\
\text { which are non-obvious or surprising.' }\end{array}$ & $\begin{array}{l}\text { Crilly and Cardoso } \\
\text { (2017) }\end{array}$ & Design Studies \\
\hline $\begin{array}{l}\text { 'Creativity is often characterized by referring to the novelty (e.g., } \\
\text { solutions have less frequent features) and utility (i.e. solutions } \\
\text { satisfy precise needs) of the solutions. Creativity in physics is } \\
\text { described by inventiveness and orderliness, and creativity in art is } \\
\text { represented by imagination and originality.' }\end{array}$ & $\begin{array}{l}\text { Doboli and Umbarkar } \\
\qquad(2014)\end{array}$ & Design Studies \\
\hline $\begin{array}{l}\text { 'The action events that are novel in the context of a collaborative } \\
\text { environment.' }\end{array}$ & $\begin{array}{l}\text { D'Souza and Dastmalchi } \\
\text { (2016) }\end{array}$ & Design Studies \\
\hline 'Novelty, value, and surprise.' & Grace et al. (2015) & $\begin{array}{l}\text { International Journal of Design } \\
\text { Creativity and Innovation }\end{array}$ \\
\hline 'Useful, novel and surprising.' & Kelly and Gero (2017) & $\begin{array}{l}\text { International Journal of Design } \\
\text { Creativity and Innovation }\end{array}$ \\
\hline $\begin{array}{l}\text { 'A measure of value or novelty which is expressed (or made } \\
\text { tangible or visible) in a design.' }\end{array}$ & Lee et al. (2015) & $\begin{array}{l}\text { International Journal of Design } \\
\text { Creativity and Innovation }\end{array}$ \\
\hline 'Three characteristics: novelty, usefulness and surprising.' & $\begin{array}{l}\text { Mahdizadeh Hakak et } \\
\text { al. (2016) }\end{array}$ & $\begin{array}{l}\text { International Journal of Design } \\
\text { Creativity and Innovation }\end{array}$ \\
\hline $\begin{array}{l}\text { 'A process to evaluate a problem in an unexpected or unusual } \\
\text { fashion in order to generate ideas that are novel. Also, creativity } \\
\text { (noun) refers to novelty and originality.' }\end{array}$ & Oman et al. (2013) & $\begin{array}{l}\text { Research in Engineering } \\
\text { Design }\end{array}$ \\
\hline 'Original, appropriate, and unexpected.' & Snider et al. (2016) & $\begin{array}{l}\text { Research in Engineering } \\
\text { Design }\end{array}$ \\
\hline 'The ability to produce something that is both novel and useful.' & Sosa and Marle (2013) & Journal of Mechanical Design \\
\hline $\begin{array}{l}\text { 'Newness (or difference) and task appropriateness (or } \\
\text { usefulness).' }\end{array}$ & $\operatorname{Tan}(2016)$ & $\begin{array}{l}\text { International Journal of Design } \\
\text { Creativity and Innovation }\end{array}$ \\
\hline $\begin{array}{l}\text { 'The production of novel, useful products, or ideas that are both } \\
\text { original and feasible.' }\end{array}$ & Toh and Miller (2015) & Design Studies \\
\hline $\begin{array}{l}\text { 'The process of developing new and original ideas that are } \\
\text { somehow appropriate for a specific function, or occasion, thus } \\
\text { bringing value to prospective users or adopters.' }\end{array}$ & $\begin{array}{l}\text { Valgeirsdottir et al. } \\
\qquad(2015)\end{array}$ & $\begin{array}{l}\text { International Journal of Design } \\
\text { Creativity and Innovation }\end{array}$ \\
\hline
\end{tabular}

As shown in Table 1 above, the definitions of creativity used by different design researchers are various. Demirkan and Afacan (2012) indicated that the nature of creativity is so complex that there is no single definition for encompassing and identifying this concept. Rodgers and Jones (2017) explored the difficulties of defining and conceptualising creativity among design tutors and design students. Novelty and usefulness (or valuable) were considered to be the two core elements of creativity (Sarkar 
and Chakrabarti, 2007). As shown in Table 1, 'surprise' has been increasingly considered to be a third characteristic of creativity in recent years. It is used to describe the notion of evoking unexpectedness and astonishment which are not involved in 'novelty' (Grace et al., 2015). Therefore, based on the definitions of creativity involved in this section, the three core elements of the definition of creativity are novelty, usefulness and surprise.

However, none of the 14 definitions listed above involves 'aesthetics'. Only one of them involves 'functionality', of which creativity is defined as 'The process of developing new and original ideas that are somehow appropriate for a specific function ...' (Valgeirsdottir et al., 2015). Therefore, metrics of creativity assessment are explored in the next section to investigate whether 'aesthetics' and 'functionality' are involved in creativity assessment.

\section{METRICS OF CREATIVITY ASSESSMENTS}

Creativity assessment is vital to the selection of creative ideas and products, as well as the identification of better inventors and designers (Sarkar and Chakrabarti, 2011). Metrics have been used extensively for decades in creativity assessment. This section demonstrates several popular creativity assessment methods using metrics.

Novelty, quantity, quality and variety are the four metrics proposed by Shah et al. (2003) for creativity evaluation, which is often used to assess a method or a process. Novelty indicates that an idea is new to an individual or to the history. Quality refers to the feasibility of an idea. Quantity is the total number of ideas produced by an individual or a group, and variety is the number of idea categories produced. In this method, novelty and quality reflects the creativity of an idea or a product produced. Similar to Shah et al.'s (2003) method, Lopez et al. (2011) proposed variety, quantity, novelty and feasibility, and Plucker and Makel (2010) used fluency, flexibility, originality, and elaborations to assess creativity.

Sarkar and Chakrabarti (2011) proposed a method to assess the creativity of an idea or a product through evaluating novelty and usefulness. Novelty involves both something new and original, while usefulness indicates social value. In this method, novelty is assessed by employing the FBS model and SAPPhIRE model (Chakrabarti et al., 2005), of which 'function' plays a vital role. Usefulness is calculated by the equation 'Usefulness $(\mathrm{U})=$ Level of importance $(\mathrm{L}) \times$ Rate of popularity of use $(\mathrm{R}) \times$ Frequency of usage $(\mathrm{F}) \times$ Duration of use or Duration of benefit per usage (D)'. The overall creativity of a product is calculated by 'Creativity $(\mathrm{C})=$ Novelty $(\mathrm{N}) \times$ Usefulness (U)'.

Chiu and Shu (2012) applied novelty, usefulness and cohesiveness to assess the creativity of individual concepts. In this approach, novelty refers to newness, originality and surprise. Usefulness refers to appropriateness and value. Cohesiveness refers to wholeness, elaboration and clarity.

Creative Product Semantic Scale (CPSS), proposed by O'Quin and Besemer (1989), measures a design idea in three conceptual dimensions: novelty, resolution, and elaboration and synthesis. Novelty involves original, surprising and germinal; resolution involves valuable, logical and useful; and elaboration and synthesis involve organic, elegant, complex understandable, and well-crafted. However, in the CPSS creativity assessment questionnaire proposed by Chulvi et al. (2012), elaboration and synthesis were not considered. This new version of CPSS questionnaire is mainly focused on novelty and resolution or utility.

Verhaegen et al. (2013) showed a high-level overview of metrics used for assessing the creativity of ideas as well as idea generation methods, which was based on the studies conducted by Shah et al. (2000) and Dean et al. (2006). Quantity, variety, novelty and quality are the four metrics used for assessing creativity in this study. Novelty refers to originality and paradigm relatedness, and quality refers to workability, relevance and specificity.

Demirkan and Afacan (2012) proposed three factors, involving 31 items, for creativity assessment. The first factor is known as novelty and affective characteristics of the artefact, which is associated with the shape of design. This factor involves items such as new, novel, unusual, different, and shape. The second factor is named as elaboration characteristics of the artefact, which is related to geometric and figure-ground relations as well as harmony of design elements. It involves metrics such as integrated, polished, geometric, balanced and harmony. The last factor is known as design principles, involving items such as rhythm, order, repetition, unity and number.

Christensen and Ball (2016) indicated originality, functionality and aesthetics are the core dimensions of creativity assessment. The assessment of originality involves identifying and comparing designs to 
explore novel concepts. The assessment of functionality measures the usefulness of a design, that is, whether the design can meet objective criteria or requirement. Assessing aesthetics is related to the perceptual interaction with the design object in terms of eliciting emotion responses. However, this method is not a conventional creativity assessment approach using metrics.

As illustrated above, various sets of creativity assessment metrics are proposed. Novelty and usefulness are the two core metrics used in creativity assessment. Novelty refers to newness and originality, while some researchers also suggested surprise. Usefulness involves the feasibility and value of an idea. The metrics used for creativity assessment are in line with the definitions of creativity illustrated in the previous section. Similarly, 'functionality' and 'aesthetics' are not often discussed within these assessment metrics. Among the metrics shown above, Sarkar and Chakrabarti (2011) indicated 'function' as a significant element in novelty assessment. The three dimensions of creativity assessment, indicated by Christensen and Ball (2016), involves functionality, aesthetics and originality. However, this method is not a conventional metric-based assessment approach, and it indicated assessing functionality is equivalent to assessing usefulness. The CPSS (O'Quin and Besemer, 1989) involves aspects of aesthetics, but a later version of the CPSS proposed by Chulvi et al. (2012) has omitted the metrics related to aesthetics. The metrics proposed by Demirkan and Afacan (2012) involve items of aesthetics, but this set of metrics was used to assess the creativity of paintings rather than products. Section 2 and 3 have explored the definitions and assessment metrics of creativity in the design context, and have indicated novelty, usefulness and surprise are the three core elements of design creativity. Nevertheless, the relationship between functionality, aesthetics and creativity still remains unclear.

\section{CASE STUDY}

\subsection{Case Study Methods}

In order to explore the relationship between functionality, aesthetics and creativity in product design, we have conducted a case study on the design of chairs. A chair is an ideal product representing the value of both functional and aesthetics in the design. It is considered a tangible artefact that embodies a broadly technological problem solving process producing functional and aesthetic solutions (Cropley and Kaufman, 2018). Chair designs are often used as example projects in design research, for instance by Hung and Chen (2012) and Cropley and Kaufman (2018). The metrics investigated in this case study were: novelty, usefulness, surprise, functionality, and aesthetics, of which novelty, usefulness and surprise are the core elements of creativity. In addition to the five metrics, the overall creativity of each sample was explored as well.

Based on the explorations illustrated in the previous sections, in this case study novelty refers to newness and originality, usefulness refers to feasibility and value, surprise refers to unexpectedness and astonishment, functionality refers to performance, aesthetics refers to visual and ergonomics, and creativity refers to the outcome of 'the process by which something so judged (to be creative) is produced'.

In this study, the chair design samples were selected from the winners of international design competitions, such as the Red Dot and iF design awards, through random purposive sampling. A number of studies have shown positive results of using samples from the winners of design awards. For example, the winning formulas for metaphor design (Wang, 2016), the 77 evidence-based design heuristics (Yilmaz et al., 2016), the three-driven approaches of combinational creativity (Han et al., 2019), and the conceptual distances in combinational creativity (Han et al., 2018b). Design competitions might lack rigorous creativity evaluations, but Wang and Chan (2010) indicted design competitions are creativity-oriented. Furthermore, functionality and aesthetics are core to the judging criteria of design competitions, such as the Red Dot and iF design awards. Exploring samples selected from winners of design competitions, therefore, is reliable for this study. The samples can be considered creative products that involve aspects of both functionality and aesthetics.

This case study employed means of expert evaluation for exploring the relations between functionality, aesthetics and creativity, as well as novelty, usefulness and surprise. The use of experts in creativity assessment is a dominant approach in design research, for example, the research projects conducted by Sarkar and Chakrabarti (2011), Chulvi et al. (2012), and Cropley and Kaufman (2018). Thus, employing experts as evaluators to evaluate the design samples is a suitable and reliable method for this study. 
The details of the chair samples, such as the names, images and descriptions, were provided to the expert evaluators, as shown in Figure 1. Based on the information provided, the participants were required to rate the samples according to the novelty, usefulness, surprise, functionality, aesthetics, and the overall creativity of the chair designs. The rating is based on a 7-point Likert scale, ranging from 'poor' ( 1 ) through 'moderate' (4) and up to 'excellent' (7).

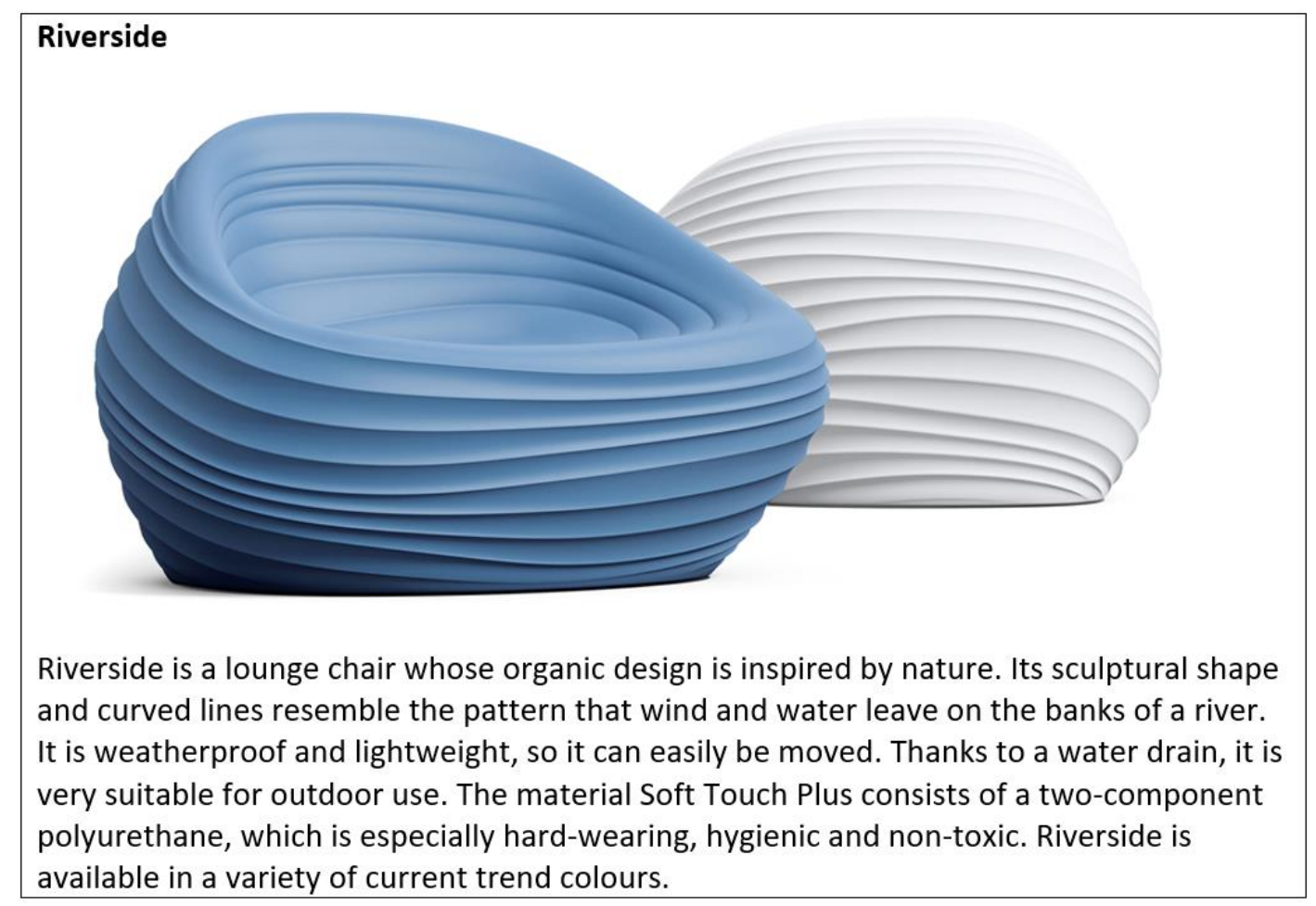

Figure 1. An example of the samples involved in the case study

\subsection{Case Study Process and Results}

Eleven experts, with a mean age of 29.6 (Standard Deviation $(S D)=3.5$ ) and a mean design experience of 7.1 years $(S D=3.6)$, were involved in the evaluation of this case study. The experts participated in the evaluation voluntarily with intrinsic motivations. Although the number of experts seems low, there are no common agreements on the number of experts required for an evaluation (Lai et al., 2006). Comparing with general evaluators, the required number of expert evaluators is far less (Achiche et al., 2013). For instance, Charyton and Merrill (2009) only employed two experts for evaluating creativity and engineering designs.

Ten chair designs were selected from the winners of the Red Dot and iF design awards and the details of the samples were provided to the experts for evaluation using the rating methods illustrated above. In the case study, six metrics: novelty, usefulness, surprise, functionality, aesthetics, and creativity of each sample are required to be measured. The ten chair design samples were assessed by the eleven experts individually based on their knowledge and experience, in order to increase the robustness of the evaluation results.

A Cronbach's alpha was conducted to measure the internal consistency of the evaluation scores. The overall Cronbach's alpha is 0.909 , indicating an excellent internal consistency. This showed a good reliability of the expert evaluation. As a consequence, the mean values of the six metrics of each sample, rated by the eleven experts, were employed for further analysis, as shown in Table 2.

A Pearson's Correlation test was conducted to measure the strength and direction of relations existing between the six metrics. The correlation calculations were based on the mean metric scores, rated by the experts, of the ten chair designs, as provided in Table 2. The results of the Pearson's Correlation test is shown in Table 3. In the table, a negative coefficient of the correlation indicates an increase in an independent metric will result in a decrease in the dependent metric, and vice versa. A positive correlation coefficient implies one metric increases while the other increases. Furthermore, there is only a statistically significant correlation between the two metrics when $* * p<.001$. 
Table 2. Results of the expert evaluation (mean values)

\begin{tabular}{|c|c|c|c|c|c|c|}
\hline $\begin{array}{c}\text { Metric } \\
\text { Sample }\end{array}$ & $\begin{array}{c}\text { Mean } \\
\text { Novelty }\end{array}$ & $\begin{array}{c}\text { Mean } \\
\text { Usefulness }\end{array}$ & $\begin{array}{c}\text { Mean } \\
\text { Functionality }\end{array}$ & $\begin{array}{c}\text { Mean } \\
\text { Aesthetics }\end{array}$ & $\begin{array}{c}\text { Mean } \\
\text { Surprise }\end{array}$ & $\begin{array}{c}\text { Mean } \\
\text { Creativity }\end{array}$ \\
\hline $\mathbf{1}$ & 5.45 & 4.27 & 4.64 & 5.55 & 5.18 & 4.91 \\
\hline $\mathbf{2}$ & 3.18 & 5.27 & 5.27 & 4.27 & 2.55 & 3.36 \\
\hline $\mathbf{3}$ & 3.64 & 4.36 & 4.36 & 3.36 & 3.18 & 3.55 \\
\hline $\mathbf{4}$ & 5.82 & 5.09 & 5.09 & 3.73 & 5.45 & 5.18 \\
\hline $\mathbf{5}$ & 5.09 & 5.09 & 5.18 & 5.18 & 4.27 & 4.73 \\
\hline $\mathbf{6}$ & 5.27 & 3.91 & 3.82 & 4.64 & 5.09 & 4.64 \\
\hline $\mathbf{7}$ & 5.45 & 5.45 & 5.27 & 5.36 & 4.64 & 4.64 \\
\hline $\mathbf{8}$ & 3.09 & 5.73 & 5.91 & 4.36 & 2.09 & 2.73 \\
\hline $\mathbf{9}$ & 6.18 & 4.27 & 4.27 & 6.00 & 5.91 & 5.73 \\
\hline $\mathbf{1 0}$ & 5.09 & 5.09 & 5.36 & 4.36 & 4.18 & 4.45 \\
\hline
\end{tabular}

Table 3. Results of the Pearson's Correlation test

\begin{tabular}{|c|c|c|c|c|c|c|}
\hline Variable & Novelty & Usefulness & Surprise & Functionality & Aesthetics & Creativity \\
\hline Novelty & 1 & & & & & \\
\hline Usefulness & -0.408 & 1 & & & & \\
\hline Surprise & $0.978 * *$ & -0.559 & 1 & & & \\
\hline Functionality & -0.416 & $0.964 * *$ & -0.568 & 1 & & \\
\hline Aesthetics & 0.558 & -0.178 & 0.513 & -0.150 & 1 & \\
\hline Creativity & $0.976 * *$ & -0.475 & $0.977^{* *}$ & -0.483 & 0.561 & 1 \\
\hline
\end{tabular}

$* * p<.001$

\subsection{Discussions}

Novelty, usefulness and surprise are claimed to be the three core elements of design creativity based on exploring various definitions and assessment methods of creativity in the design domain. As shown in table 3, there are statistically significant positive and strong correlations between novelty and creativity $\left(r=0.976^{* *}\right)$, as well as between surprise and creativity $\left(r=0.977^{* *}\right)$. Although, there is a negative correlation between usefulness and creativity, the correlation is not statistically significant. Furthermore, the correlation between novelty and surprise is strongly positive ( $\left.r=0.978^{* *}\right)$, which is statistically significant. Grace et al. (2015) described surprise as distinct from novelty, but it seems surprise is strongly correlated to novelty according to the participant's perception of novelty. Cropley and Kaufman (2018) suggested that a correlation coefficient of greater than 0.8 indicates redundancy in general. It therefore suggests that surprise and novelty are measuring the same construct. Therefore, creativity is strongly and positively related to novelty, but not significantly correlated with usefulness, concerning the case study conducted. However, the high correlation coefficient between creativity and novelty indicates the two metrics are measuring the same construct.

Simultaneously, one can see that there is a negative correlation between functionality and creativity, while there is a positive correlation between aesthetics and creativity. Both of these correlations, however, are not statistically significant. A further exploration of the correlations between functionality, aesthetics and the three core elements of creativity show that there is only a significant correlation, which is strong and positive $(r=0.964 * *)$, between functionality and usefulness. This therefore suggests functionality and usefulness are measuring the same construct.

The results of this case study imply that there are no statistically significant correlations between creativity and functionality as well as aesthetics. Concerning the relations between creativity and the three core elements of creativity, there is only a strong and positive correlation between creativity and novelty, but the high correlation coefficient suggests creativity and novelty are measuring the same construct. Furthermore, due to the high values of correlation coefficients, it is suggested that novelty and surprise are measuring the same construct, as well as functionality and usefulness. 


\section{CONCLUSIONS}

This paper has shown that novelty, usefulness and surprise are the three core elements of design creativity. This result was achieved by investigating a number of related studies on creativity definitions and assessments. A new case study conducted as part of this research as presented in this paper further explored the relations between functionality, aesthetics and creativity involving the three core elements. The results indicate that creativity is not statistically significantly correlated to functionality or aesthetics, concerning a limited number of samples. In other words, there are no tangible relations between creativity, functionality, and aesthetics. In addition, the findings of the case study conducted suggest that creativity and novelty are measuring the same construct. To some extent, this research outcome might imply that creativity in design is actually overrated. As a consequence, new definitions and new approaches for assessing design creativity should be explored in future research. Although, the findings in this paper allow for a better understanding or comprehension of creativity in the context of design, creativity still remains an elusive phenomenon requiring further exploration. A further study employing more evaluators and various other types of design samples is planned to provide these additional insights.

\section{REFERENCES}

Achiche, S., Appio, F.P., McAloone, T.C. and Di Minin, A. (2013), "Fuzzy decision support for tools selection in the core front end activities of new product development", Research in Engineering Design, Vol. 24 No. 1, pp.1-18. https://doi.org/10.1007/s00163-012-0130-4

Amabile, T.M. (1983), The social psychology of creativity, Springer-Verlag, New York, USA.

Boden, M.A. (2004), The creative mind: Myths and mechanisms, 2 edn, Routledge, London, UK.

Carruthers, P. (2011), "Creative action in mind", Philosophical Psychology, Vol. 24 No. 4, pp. 437-461. https://doi.org/10.1080/09515089.2011.556609

Chakrabarti, A. and Bligh, T.P. (2001), "A scheme for functional reasoning in conceptual design”, Design Studies, Vol. 22, pp. 493-517. https://doi.org/10.1016/S0142-694X(01)00008-4

Chakrabarti, A., Sarkar, P., Leelavathamma, B. and Nataraju, B.S. (2005), "A functional representation for aiding biomimetic and artificial inspiration of new ideas", Artificial Intelligence for Engineering Design, Analysis and Manufacturing, Vol. 19 No. 2, pp. 113-132. https://doi.org/10.1017/S0890060405050109

Charyton, C. and Merrill, J.A. (2009), "Assessing general creativity and creative engineering design in first year engineering students", Journal of Engineering Education, Vol. 98 No. 2, pp. 145-156. https://doi.org/10.1002/j.2168-9830.2009.tb01013.x

Childs, P.R.N. (2018), Mechanical design engineering handbook, 2nd edn, Butterworth-Heinemann, Oxford, UK.

Childs, P.R.N., Hamilton, T., Morris, R.D. and Johnston, G. (2006), "Centre for technology enabled creativity", DS 38: Proceedings of E\&DPE 2006, the 8th International Conference on Engineering and Product Design Education, Salzburg, Austria, 07.-08.09.2006.

Chiu, I. and Shu, L.H. (2012), "Investigating effects of oppositely related semantic stimuli on design concept creativity", Journal of Engineering Design, Vol. 23 No. 4, pp. 271-296. https://doi.org/10.1080/09544828.2011.603298

Christensen, B.T. and Ball, L.J. (2016), "Dimensions of creative evaluation: Distinct design and reasoning strategies for aesthetic, functional and originality judgments", Design Studies, Vol. 45, pp. 116-136. https://doi.org/10.1016/j.destud.2015.12.005

Chulvi, V., Sonseca, Á., Mulet, E. and Chakrabarti, A. (2012), "Assessment of the Relationships Among Design Methods, Design Activities, and Creativity", Journal of Mechanical Design, Vol. 134 No. 11, pp. 111004111004-111011. https://doi.org/10.1115/1.4007362

Couger, J.D., Higgins, L.F. and McIntyre, S.C. (1993), “(Un)Structured Creativity in Information Systems Organizations”, MIS Quarterly, Vol. 17 No. 4, pp. 375-397. https://doi.org/10.2307/249584

Craft, A. (2003), "The Limits to Creativity in Education: Dilemmas for the Educator", British Journal of Educational Studies, Vol. 51 No. 2, pp. 113-127. https://doi.org/10.1111/1467-8527.t01-1-00229

Crilly, N., Moultrie, J., Clarkson, P.J. (2004), "Seeing things: consumer response to the visual domain in product design", Design Studies, Vol. 25, pp. 547-577. https://doi.org/10.1016/j.destud.2004.03.001

Crilly, N. (2015), "Fixation and creativity in concept development: The attitudes and practices of expert designers", Design Studies, Vol. 38, pp. 54-91. http://dx.doi.org/10.1016/j.destud.2015.01.002

Crilly, N. and Cardoso, C. (2017), "Where next for research on fixation, inspiration and creativity in design?" Design Studies, Vol. 50, pp. 1-38. https://doi.org/10.1016/j.destud.2017.02.001

Cropley, D.H. and Kaufman, J.C. (2018), "The siren song of aesthetics? Domain differences and creativity in engineering and design", Proceedings of the Institution of Mechanical Engineers, Part C: Journal of Mechanical Engineering Science. https://doi.org/10.1177/0954406218778311 
Cross, N. (2011), Design thinking: Understanding how designers think and work, Berg Publishers, New York, USA.

D'Souza, N. and Dastmalchi, M.R. (2016), “Creativity on the move: Exploring little-c (p) and big-C (p) creative events within a multidisciplinary design team process", Design Studies, Vol. 46, pp. 6-37. https://doi.org/10.1016/j.destud.2016.07.003

Dean, D.L., Hender, J.M., Rodgers, T.L. and Santanen, E.L. (2006), "Identifying quality, novel, and creative ideas: Constructs and scales for idea evaluation", Journal of the Association for Information Systems, Vol. 7, No. 10, pp. 646-699.

Demirkan, H. and Afacan, Y. (2012), “Assessing creativity in design education: Analysis of creativity factors in the first-year design studio", Design Studies, Vol. 33 No. 3, pp. 262-278. https://doi.org/10.1016/j.destud.2011.11.005

Doboli, A. and Umbarkar, A. (2014), "The role of precedents in increasing creativity during iterative design of electronic embedded systems”, Design Studies, Vol. 35 No. 3, pp. 298-326. https://doi.org/10.1016/j.destud.2014.01.001

Grace, K., Maher, M.L., Fisher, D. and Brady, K. (2015), "Data-intensive evaluation of design creativity using novelty, value, and surprise", International Journal of Design Creativity and Innovation, Vol. 3 No. 3-4, pp. 125-147. https://doi.org/10.1080/21650349.2014.943295

Hagtvedt, H. and Patrick, V.M. (2014), "Consumer Response to Overstyling: Balancing Aesthetics and Functionality in Product Design”, Psychology \& Marketing, Vol. 31 No. 7, pp. 518-525. https://doi.org/10.1002/mar.20713

Han, J., Shi, F., Chen, L. and Childs, P.R.N. (2018a), “A computational tool for creative idea generation based on analogical reasoning and ontology", Artificial Intelligence for Engineering Design, Analysis and Manufacturing, Vol. 32 No. 4, pp. 462-477. https://doi.org/10.1017/S0890060418000082

Han, J., Shi, F., Park, D., Chen, L. and Childs, P. (2018b), "The conceptual distances between ideas in combinational creativity”, DS92: Proceedings of the DESIGN 2018 15th International Design Conference, pp. 1857-1866. https://doi.org/10.21278/idc.2018.0264

Han, J., Park, D., Shi, F., Chen, L., Hua, M. and Childs, P.R. (2019), “Three driven approaches to combinational creativity: Problem-, similarity- and inspiration-driven”, Proceedings of the Institution of Mechanical Engineers, Part C: Journal of Mechanical Engineering Science. Vol. 233 No. 2, pp. 373-384. https://doi.org/10.1177/0954406217750189

Hsiao, Y. and MacDonald, M.C. (2013), "Experience and generalization in a connectionist model of Mandarin Chinese relative clause processing", Frontiers in Psychology, Vol. 4, pp. 767. https://doi.org/10.3389/fpsyg.2013.00767

Hung, W.-K. and Chen, L.-L. (2012), "Effects of Novelty and Its Dimensions on Aesthetic Preference in Product Design”, International Journal of Design Creativity and Innovation, Vol. 6 No. 2, pp. 81-90.

Kelly, N. and Gero, J.S. (2017), "Generate and situated transformation as a paradigm for models of computational creativity", International Journal of Design Creativity and Innovation, Vol. 5 No. 3-4, pp. 149-167. https://doi.org/10.1080/21650349.2016.1203821

Koestler, A. (1964), The act of creation, Hutchinson, London.

Lai, H.-H., Lin, Y.-C., Yeh, C.-H. and Wei, C.-H. (2006), "User-oriented design for the optimal combination on product design”, International Journal of Production Economics, Vol. 100 No. 2, pp. 253-267.

Lee, J.H., Gu, N. and Ostwald, M.J. (2015), “Creativity and parametric design? Comparing designer's cognitive approaches with assessed levels of creativity”, International Journal of Design Creativity and Innovation, Vol. 3 No. 2, pp. 78-94. https://doi.org/10.1080/21650349.2014.931826

Lopez, R., Linsey, J.S. and Smith, S.M. (2011), "Characterizing the effect of domain distance in design-byanalogy", 23rd International Conference on Design Theory and Methodology; 16th Design for Manufacturing and the Life Cycle Conference. https://doi.org/10.1115/detc2011-48428

Mahdizadeh Hakak, A., Bhattacharya, J., Biloria, N. and Ahmadi Venhari, A. (2016), "The Proto-Fuse project: methods to boost creativity for architects", International Journal of Design Creativity and Innovation, Vol. 4 No. 3-4, pp. 206-221. https://doi.org/10.1080/21650349.2015.1021838

Mumford, M.D. (2003), “Taking stock in taking stock", Creativity Research Journal, Vol. 15, pp. 147-151.

O'Quin, K. and Besemer, S.P. (1989), “The development, reliability, and validity of the revised creative product semantic scale", Creativity Research Journal, Vol. 2 No. 4, pp. 267-278. https://doi.org/10.1080/10400418909534323

Oman, S.K., Tumer, I.Y., Wood, K. and Seepersad, C. (2013), “A comparison of creativity and innovation metrics and sample validation through in-class design projects", Research in Engineering Design, Vol. 24 No. 1, pp. 65-92. https://doi.org/10.1007/s00163-012-0138-9

Orsborn, S., Cagan, J. and Boatwright, P. (2009), "Quantifying Aesthetic Form Preference in a Utility Function", Journal of Mechanical Design, Vol. 131 No. 6, pp. 061001-061001-061010. https://doi.org/10.1115/1.3116260 
Perez Mata, M., Ahmed-Kristensen, S., Brockhoff, P.B. and Yanagisawa, H. (2017), "Investigating the influence of product perception and geometric features", Research in Engineering Design, Vol. 28 No. 3, pp. 357379. https://doi.org/10.1007/s00163-016-0244-1

Plucker, J.A. and Makel, M.C. (2010), Assessment of creativity, in J.C. Kaufman and R.J. Sternberg (eds), The Cambridge handbook of creativity, The Cambridge University Press, Cambridge, UK, pp. 48-73.

Pringle, H. (2013), "The origins of creativity”, Scientific American, Vol. 23 pp. 4-11. https://doi.org/10.1038/scientificamericancreativity1213-4

Rahman, O., Jiang, Y. and Liu, W.-s. (2010), "Evaluative Criteria of Denim Jeans: A Cross-national Study of Functional and Aesthetic Aspects", The Design Journal, Vol. 13 No. 3, pp. 291-311. https://doi.org/10.2752/146069210X12766130824894

Rhodes, M. (1961), “An Analysis of Creativity”, The Phi Delta Kappan, Vol. 42 No. 7, pp. 305-310.

Rodgers, P.A. and Jones, P. (2017), “Comparing University Design Students' and Tutors' Perceptions of Creativity”, The Design Journal, Vol. 20 No. 4, pp. 435-457. https://doi.org/10.1080/14606925.2017.1323503

Sarkar, P. and Chakrabarti, A. (2007), "Development of a method for assessing design creativity", Proceedings of the 16th International Conference on Engineering Design (ICED07), Paris, France.

Sarkar, P. and Chakrabarti, A. (2011), “Assessing design creativity”, Design Studies, Vol. 32 No. 4, pp. 348383. https://doi.org/10.1016/j.destud.2011.01.002

Shah, J.J., Kulkarni, S.V. and Vargas-Hernandez, N. (2000), "Evaluation of Idea Generation Methods for Conceptual Design: Effectiveness Metrics and Design of Experiments", Journal of Mechanical Design, Vol. 122 No. 4, pp. 377-384. https://doi.org/10.1115/1.1315592

Shah, J.J., Smith, S.M. and Vargas-Hernandez, N. (2003), "Metrics for measuring ideation effectiveness", Design Studies, Vol. 24 No. 2, pp. 111-134. https://doi.org/10.1016/s0142-694x(02)00034-0

Snider, C., Dekoninck, E. and Culley, S. (2016), "Beyond the concept: characterisations of later-stage creative behaviour in design”, Research in Engineering Design, Vol. 27 No. 3, pp. 265-289. https://doi.org/10.1007/s00163-016-0218-3

Sonderegger, A. and Sauer, J. (2010), "The influence of design aesthetics in usability testing: Effects on user performance and perceived usability", Applied Ergonomics, Vol. 41, pp. 403-410. https://doi.org/10.1016/j.apergo.2009.09.002

Sosa, M.E. and Marle, F. (2013), “Assembling Creative Teams in New Product Development Using Creative Team Familiarity”, Journal of Mechanical Design, Vol. 135 No. 8, pp. 081009-081009-081013. https://doi.org/10.1115/1.4024763

Sternberg, R.J. and Lubart, T.I. (1998), The Concept of Creativity: Prospects and Paradigms, in R.J. Sternberg (ed.), Handbook of Creativity, Cambridge University Press, Cambridge, pp. 3-15.

Sylcott, B., Cagan, J. and Tabibnia, G. (2013), "Understanding Consumer Tradeoffs Between Form and Function Through Metaconjoint and Cognitive Neuroscience Analyses", Journal of Mechanical Design, Vol. 135 No. 10, pp. 101002-101002-101013. https://doi.org/10.1115/1.4024975

Tan, C. (2016), "Understanding creativity in East Asia: insights from Confucius' concept of junzi”, International Journal of Design Creativity and Innovation, Vol. 4 No. 1, pp. 51-61. https://doi.org/10.1080/21650349.2015.1026943

Taura, T. and Nagai, Y. (2017), "Creativity in Innovation Design: the roles of intuition, synthesis, and hypothesis", International Journal of Design Creativity and Innovation, Vol. 5 No. 3-4, pp. 131-148. https://doi.org/10.1080/21650349.2017.1313132

Thompson, G. and Lordan, M. (1999), "A review of creativity principles applied to engineering design", Proceedings of the Institution of Mechanical Engineers, Part E: Journal of Process Mechanical Engineering, Vol. 213 No. 1, pp. 17-31. https://doi.org/10.1243/0954408991529960

Toh, C.A. and Miller, S.R. (2015), "How engineering teams select design concepts: A view through the lens of creativity", Design Studies, Vol. 38, pp. 111-138. https://doi.org/10.1016/j.destud.2015.03.001

Valgeirsdottir, D., Onarheim, B. and Gabrielsen, G. (2015), "Product creativity assessment of innovations: considering the creative process", International Journal of Design Creativity and Innovation, Vol. 3 No. 2 , pp. 95-106. https://doi.org/10.1080/21650349.2014.954626

Verhaegen, P.-A., Vandevenne, D., Peeters, J. and Duflou, J.R. (2013), "Refinements to the variety metric for idea evaluation", Design Studies, Vol. 34 No. 2, pp. 243-263. https://doi.org/10.1016/j.destud.2012.08.003

Wang, H.-H. (2016), "Winning formulas for metaphor design: A case study of design competitions", DS 84: Proceedings of the DESIGN 2016 14th International Design Conference.

Wang, H.-H. and Chan, J.-H. (2010), An Approach to Measuring Metaphoricity of Creative Design, in T. Taura and Y. Nagai (eds), Design creativity 2010, Springer London, London, pp. 89-96.

Yilmaz, S., Daly, S.R., Seifert, C.M. and Gonzalez, R. (2016), "Evidence-based design heuristics for idea generation”, Design Studies, Vol. 46, pp. 95-124. https://doi.org/10.1016/j.destud.2016.05.001 